\title{
EFEITOS DE DOIS PROTOCOLOS DE TREINAMENTO FÍSICO SOBRE O PESO CORPORAL E A COMPOSIÇÃO CORPORAL DE MULHERES OBESAS
}

\author{
Vanise dos Santos Ferreira Viero \\ Mestranda em Saúde Coletiva, Universidade do Extremo Sul Catarinense, \\ vanisedossantos@hotmail.com \\ Joni Marcio de Farias \\ Doutor, Universidade do Extremo Sul Catarinense, \\ jmf@unesc.net
}

\section{RESUMO}

A obesidade é uma doença crônica classificada como epidêmica, tendo apresentado importante aumento na sua prevalência nas últimas décadas, em diversos países, em todas as faixas etárias e níveis econômicos (REIS FILHO et al., 2008; ENES; SLATER, 2010). No Brasil, a prevalência do sobrepeso e da obesidade vem acompanhando a tendência mundial. Essa doença tem sido associada ao surgimento de diversas doenças crônicas não transmissíveis, principalmente em indivíduos em que o maior acúmulo de gordura se observa na regiáo abdominal (obesidade central) (ROCCA et al., 2008; ENES; SLATER, 2010). Considerada como multifatorial, tem como característica para o seu surgimento o desbalanço entre consumo e gasto energético, fatores sociais, econômicos, culturais, comportamentais, bioquímicos e moleculares, o que dificulta a sua total compreensão. No entanto, os exercícios físicos têm papel importante no seu tratamento. Para Hauser, Benetti e Rebelo (2004), o aumento do gasto diá- 
rio de energia, a redução do apetite, o aumento da taxa metabólica de repouso, o aumento da massa muscular, o aumento do efeito térmico de uma refeição, a elevação do consumo de oxigênio, a otimização dos índices de mobilização e a utilização de gordura, bem como a sensação de autossuficiência e bem-estar promovidos pelos exercícios físicos, podem contribuir para a diminuição do peso corporal. A utilização dos exercícios físicos como estratégia complementar na prevenção, no controle e no tratamento da obesidade tem despertado grande interesse da comunidade científica, incentivando vários estudos para melhorar a compreensão dos processos pelos quais o exercício físico age como terapêutico dessa doença. Diante disso, esse estudo tem como objetivo verificar os efeitos de dois protocolos de treinamento físico (aeróbio contínuo e resistido, com o método de circuito), durante três e seis meses, sobre o peso corporal e a composição corporal de mulheres obesas. O estudo foi realizado no ano de 2011 e a população foi constituída por mulheres voluntárias, com sobrepeso ou obesidade $(\geq 25,0 \mathrm{~kg} /$ $\mathrm{m}^{2}$ ), com idade média de 48,5 anos, participantes do Programa Emagreça Feliz, vinculado ao Grupo de Estudos e Pesquisa em Exercício e Saúde (GEPES), da Universidade do Extremo Sul Catarinense (UNESC). O protocolo do estudo foi aprovado pelo Comitê de Ética em Pesquisa com Seres Humanos da instituição, sob o Protocolo no 134/2008. Até os três meses de intervenção, a amostra foi constituída de 39 mulheres, divididas em dois grupos, conforme a adesáo ao método de treinamento, Exercício Aeróbio (EA) (n=19) e Exercício Resistido (ER) $(n=20)$. Após, houve uma perda amostral, permanecendo 22 mulheres, (EA $\mathrm{n}=13)$ e $($ ER $\mathrm{n}=9)$. A massa corporal foi avaliada com a utilização de uma balança digital da marca Filizola ${ }^{\circledR}$, com precisão de $10 \mathrm{~g}$ e capacidade máxima de 150 kg. A estatura foi aferida com um estadiômetro de parede, da marca Seca ${ }^{\circledR}$. O Índice de Massa Corpórea (IMC) foi calculado por meio do quociente da massa corporal $(\mathrm{kg})$ pela estatura $(\mathrm{m})$ ao quadrado. Para mensuração das circunferências da cintura, abdômen e quadril, utilizou-se uma fita métrica inextensível da marca Cardiomed $^{\oplus}$, escalonada em $0,1 \mathrm{~cm}$. Para avaliação da composição corporal, foi calculado o percentual de gordura por meio da mensuração das dobras cutâneas, com auxílio de um adipômetro científico da marca TOPTEC-Cescorf ${ }^{\oplus}$, de pressão constante de $10 \mathrm{~g} / \mathrm{mm}^{2}$ na superfície de contato e precisão de $1 \mathrm{~mm}$, sendo a 
densidade corporal calculada por meio das dobras cutâneas (tríceps, subescapular, suprailíaca e panturrilha), equação generalizada desenvolvida por Petroski (1995 apud PETROSKI, 2009). Na avaliação da capacidade cardiorrespiratória, foi realizado o teste de $1.600 \mathrm{~m}$ de Rockport e, na flexibilidade, foi realizado o teste sentar e alcançar, utilizando o Banco de Wells. No protocolo de treinamento, foi utilizada a intensidade de $60 \%$ a $70 \%$ da Frequência Cardíaca de Reserva (F. reserva ) como determinante para o treinamento aeróbio contínuo (caminhada), durante 45 minutos, antecedido e finalizado por alongamentos. Para o monitoramento da intensidade do esforço, utilizou-se o frequencímetro da marca Polar ${ }^{\circledR}$. O treinamento resistido em forma de circuito teve a mesma duração, além de ser antecedido e finalizado com alongamentos. Nesse, o grupo foi dividido em três estaçóes distintas, realizando três vezes o rodízio entre elas, tendo 30 segundos para a execução do exercício e 20 segundos para o descanso e deslocamento entre os aparelhos, ficando 5 minutos finais direcionados para volta à calma. A carga do treinamento no exercício resistido foi estimada pela percepção subjetiva de esforço. Os programas ocorreram três vezes por semana, no período vespertino. Os dados foram expressos em média e desvio padrão, sendo analisados estatisticamente pelo teste de normalidades de Kolmogorov Smirnov, a fim de verificar a sua homogeneidade. Quando comparado os dois grupos, foi utilizado o Teste $\mathrm{t}$-Student para amostras independentes e, quando comparado o mesmo grupo (pré e pós-treinamento), Teste t para amostras dependentes. $\mathrm{O}$ nível de significância estabelecido pelo teste estatístico foi de $\mathrm{p} \leq 0,05$, utilizando o pacote estatístico Statistical Package for the Social Sciences (SPSS), versão 18.0. Após três meses de intervenção, pôde-se observar uma diminuição significativa na circunferência abdominal, sendo no grupo ER de $105,10 \pm 10,55$ para $104,80 \pm 9,68$, e no grupo EA de $100,47 \pm 12,28$ para $96,68 \pm 12,20$. Mesmo com uma diminuição significativa da circunferência abdominal nos dois grupos, o valor médio apresentado ainda permaneceu na categoria "substancialmente aumentado", o que predispóe o surgimento de doenças, principalmente as doenças cardiovasculares. Ainda, após os três meses, observou-se diminuição significativa na circunferência da cintura apenas no grupo EA, de 90,73 $\pm 14,37$ para $86,36 \pm 11,50$. Reis Filho et al. (2008) encontraram semelhantes resultados quando compararam os efeitos 
de oito semanas de treinamento físico em circuito com pesos e caminhada, em mulheres obesas. O mesmo foi observado no estudo de Rocca et al. (2008), que avaliaram os efeitos de 12 semanas de exercício físico sobre os fatores de risco para o desenvolvimento de doenças crônicas. Após o período de intervenção, os autores concluíram que o exercício físico demonstrou ser uma importante estratégia para reduzir os fatores de risco que ajudam a desenvolver doenças crônicas em mulheres obesas. Neste presente estudo, após os seis meses de intervenção, observaram-se diminuiçôes significativas apenas no grupo $\mathrm{ER}$, nas variáveis do peso corporal (de $84,00 \pm 12,75$ para $80,22 \pm 11,44$ ) e da circunferência da cintura (de $96,70 \pm 8,45$ para 93,22 $\pm 8,5$ ). Em relação à variável da massa corporal magra, verificou-se que, após os seis meses, houve um aumento significativo dessa variável

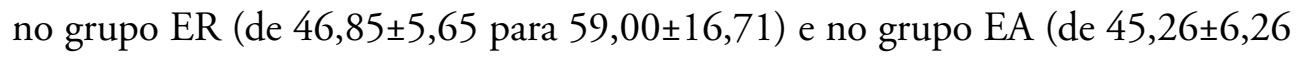

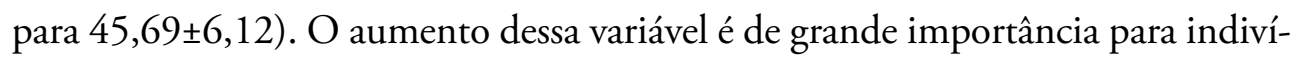
duos que estáo participando de programas de emagrecimento, pois, com o ganho da massa muscular, a taxa metabólica de repouso e o gasto energético aumentam, além de contribuir para a manutenção de peso corporal em longo prazo (GUEDES JR., 2003). Tanto os exercícios resistidos quanto os exercícios aeróbios apresentaram efeitos positivos no peso corporal e na composição corporal, após três e seis meses de intervenção, demonstrando que ações como essas são necessárias e se mostram eficazes como estratégia primária no controle e no tratamento da obesidade. Entretanto, destaca-se a necessidade de dar continuidade ao estudo, a fim de verificar o efeito crônico nesse tipo de intervenção e com essa população.

Palavras-chave: Exercício; Obesidade; Saúde.

\section{REFERÊNCIAS}

ENES, C. C.; SLATER, B. Obesidade na adolescência e seus principais fatores determinantes. Revista Brasileira de Epidemiologia, Brasília, v.13, n.1, p.163$171,2010$.

GUEDES, D. P. Musculaçáo: estética e saúde feminina. São Paulo: Phorte, 2003. 
HAUSER, C.; BENETTI, M.; REBELO, F. Estratégias para o emagrecimento. Revista Brasileira de Cineantropometria e Desempenho Humano, Brasília, v.6, n.1, p.72-81, 2004.

PETROSKI, É. L. Antropometria: técnicas e padronizaçôes. 4. ed. Porto Alegre: Palloti, 2009.

REIS FILHO, A. D. et al. Efeitos do treinamento em circuito ou caminhada após oito semanas de intervenção na composição corporal e aptidão física de mulheres obesas sedentárias. Revista Brasileira de Obesidade, Nutriçáo e Emagrecimento, Brasileira, v.2, n.11, p.498-507, 2008.

ROCCA, S. V. et al. Efeito do exercício físico nos fatores de risco de doenças crônicas em mulheres obesas. Revista Brasileira de Ciências Farmacêuticas, Brasília, v.44, n.2, p.185-192, 2008. 